\title{
Mapa geológico simplificado do estado do Rio Grande do Norte: representação cartográfica de elementos geológicos para divulgação das Geociências
}

\author{
Simplfied geological map of the State of RIO Grande do Norte: CARTOGraphic representation OF geological elementS fOR \\ USE IN GEOSCIENCES \\ Robson Rafael de Oliveira ${ }^{1}$, Marcos Antonio Leite do Nascimento² \\ 1- Instituto Federal de Educação, Ciência e Tecnologia do Rio Grande do Norte, IfRN - Campus Avançado Parelhas. Parelhas, RN - robson.oliveira@ifrn.edu.br \\ 2- Departamento de Geologia, Universidade Federal do Rio Grande do Norte. Natal, RN - marcos@geologia.ufrn.br
}

Abstract: This paper seeks to make accessible the geological language used in technical maps, and to represent cartographically, in a simplified and representative form, geological elements of Rio Grande do Norte (RN) state. This was achieved through manipulation and generalization of spatial data contained in the Geological Map of RN, 1:500,000 scale, produced by the Geological Service of Brazil, in 2006. To create the simplified cartographic material, the use of GIS as a tool for integration and analysis of geological and cartographical knowledge was key. Thematic cartography concepts were also applied, seeking to better represent data available. Cartographic products produced were the Simplified Geological Map of RN, scale 1:500,000, and different inserts in 1:2,500,000 scale. These maps are available in printed and digital format in the context of a GIS. The maps produced can be used by students, researchers, managers and decision-makers, to understand the physical environment.

\section{Introdução}

Devido os atuais padrões de consumo da sociedade, o ambiente natural tem sido explorado de modo desordenado e acelerado. Isto tem causado instabilidade dos seus sistemas de sustentação e ocasionado problemas ambientais e transtornos socioeconômicos. Frente a isto, nas últimas décadas, diversos ramos da ciência têm aliado forças para equacionar os problemas ambientais e propor medidas que garantam um desenvolvimento sustentável. Dentre estes ramos, as Geociências se preocupam em compreender o meio físico e seus processos (Borges, 2013).

O conhecimento geológico identifica, de maneira mais segura, as aptidões e restrições de uso dos recursos naturais abióticos, bem como os impactos advindos de seu manejo inadequado. Além disso, amplia o conhecimento dos recursos minerais, os riscos geológicos e as paisagens naturais compostas por tipos específicos de minerais, rochas, relevo, solos e clima (Pfaltzgraff \& Torres, 2010).
Manuscrito:

Recebido: 20/12/2017

Correção: 02/10/2018

Aceito: $27 / 12 / 2018$

Citation: Oliveira, R. R., \& Nascimento, M. A. L. (2019). Mapa Geológico Simplificado do Estado do Rio Grande do Norte: representação cartográfica de elementos geológicos para divulgação das Geociências. Terræ Didatica, 15, 1-13, e019003. doi:10.20396/ td.v15i0.8654688

Palavras-chaves: Geologia, mapas, representação cartográfica, SIG
Neste panorama, as Geociências apresentam as ferramentas básicas para a execução e implementação do desenvolvimento sustentável. No entanto, observa-se que este ramo da Ciência ainda é pouco difundido e compreendido pela sociedade em geral. Isto ocorre, em sua maior parte, pela falta de uma comunicação eficiente e significativa entre a sociedade e este tema. Boa parte do conteúdo disponibilizado ou apresenta simplificação demasiada ou fornece informações muito complexas para serem utilizadas pelo público em geral. O objeto de estudo deste artigo, o Estado do Rio Grande do Norte, situado na porção oriental do Nordeste do Brasil, apresenta sua geologia representada de dois modos extremos: o primeiro, contido em atlas escolares e livros didáticos, apresenta uma expressiva generalização do território, com a geologia apresentada de forma simplista, enquanto que o segundo, contido em trabalhos técnicos, apresenta complexa rede de informações. 
No Brasil, exemplos de representação cartográfica de elementos geológicos em linguagem acessível ao público, por meio de mapas, já foram realizados, sendo o caso do Mapa Geológico Simplificado do Brasil, na escala 1:6.000.000, publicado pelo Serviço Geológico do Brasil - CPRM (Santos et al., 2015). Neste mapa, o Brasil é segmentado, de acordo com as classes de rochas, nas unidades: Terrenos constituídos predominantemente por rochas metamórficas; Áreas com predominância de rochas ígneas vulcânicas; Áreas com predominância de rochas ígneas intrusivas; Áreas com predominância de rochas sedimentares; e Coberturas sedimentares recentes. A nível estadual tem-se o Mapa Simplificado do Estado do Rio de Janeiro (Mansur et al,. 2004) e o Mapa Geológico Simplificado do Estado de Rondônia (Iza \& Costa, 2010). Ambos levam em consideração apenas o quesito classe de rocha.

O Rio Grande do Norte possui uma geologia singular e didática, haja vista sua diversidade de elementos significativos dentro de uma ampla faixa de tempo geológico (do Arqueano até o recente). Ao longo deste século, esta sua singularidade, aliada a seu potencial econômico, rendeu diversas publicações científicas e gerou um vasto banco de informações geológicas. Espacialmente, estas informações foram representadas pelo Serviço Geológico do Brasil - CPRM no Mapa Geológico do Estado do Rio Grande do Norte, confeccionado na escala 1:500.000 e lançado em 2006 (Angelim, Medeiros \& Nesi, 2006). Neste mapa, o território do Estado é segmentado em 64 unidades litoestratigráficas e diversas estruturas tectônicas. Trata-se de um produto rico em detalhes e informações, que é extremamente útil para geocientistas, porém de difícil entendimento para a sociedade em geral.

Desta forma, a representação gráfica simplificada dos elementos geológicos encontrados no Estado do Rio Grande do Norte permite tornar a Geologia uma ciência mais acessível a sociedade, possibilitando o uso do banco de dados criado na educação, gestão territorial por parte de instituições governamentais e não governamentais e proteção ambiental.

\section{Materiais, métodos e técnicas}

Para a confecção deste trabalho foram utilizadas as seguintes fontes de informação:

\section{Mapa Geológico do Estado do Rio Grande}

do Norte, na escala 1:500.000, elaborado em 2006 pelo Serviço Geológico do Brasil CPRM (Angelim, Medeiros \& Nesi, 2006);

$\checkmark \quad$ Mapa Geodiversidade do Estado do Rio Grande do Norte, na escala 1:500.000, elaborado em 2009 pelo Serviço Geológico do Brasil - CPRM (CPRM, 2009, Pfaltzgraff \& Torres, 2010);

$\checkmark \quad$ Imagens de radar em formato raster da Shuttle Radar Topography Mission (SRTM) disponibilizados pelo Serviço Geológico dos Estados Unidos (https://earthexplorer.usgs. gov/);

$\checkmark$ Dados planimétricos do Instituto Brasileiro de Geografia e Estatística (IBGE) (https:// downloads.ibge.gov.br/downloads_geociencias.htm).

Estes mapas consistiam de versões impressas e em formato digital (shapefile, PDF, CAD).

Para o tratamento dos dados foram utilizados os programas ArcGIS 10.1 (Environmental Systems Research Institute - ESRI), Corel Draw Graphics Suite X7 (Corel Corporation) e Excel 2013 (Microsoft Corporation). Todos os dados geográficos foram reprojetados para o DATUM SIRGAS 2000, tendo em conta a vigência de tal projeção no continente americano. Reprojetados, estes dados foram separados em duas grandes categorias: dados sistemáticos e dados temáticos. Nos sistemáticos, estão inclusos aqueles que remetem à feições das cartas-base, tais como sedes municipais, localidades, vias de acesso, hidrografia e limites municipais. Enquanto que os temáticos incluem dados geológicos (estratigrafia, estruturas tectônicas, ocorrência minerais) e geomorfológicos.

Após a organização dos dados, foi realizada uma leitura visual do produto cartográfico, observando seus temas significantes e suas dificuldades interpretativas. Foram definidos os temas "tempo geológico", "classes de rochas" e "estruturas tectônicas" como os "atores" do mapa. Além disso, o excesso destes mesmos temas é um dos causadores da sobrecarga visual do produto cartográfico.

Tomando por base a literatura, foram definidos os tempos Pré-cambriano (Arqueano, Paleoproterozoico e Neoproterozoico), Mesozoico e Cenozoico como os mais representativos da história geológica do Estado do Rio Grande do Norte. Foram ainda subdivididas as classes de rocha que ocorrem no estado em: i) ígnea: plutônica e vulcânica; ii) metamórfica: ortoderivadas e paraderivadas; e ii) 
sedimentar: consolidadas siliciclásticas; consolidada carbonática e sedimentos inconsolidados.

De posse destas diretrizes, todas as 64 unidades litoestratigráficas do estado do RN foram classificadas. Por exemplo, a unidade "Metatonalito Bom Jesus" foi classificada como rocha metamórfica ortoderivada e pertencente ao eón Arqueano. Enquanto que todas as unidades do Grupo Seridó (formações Jucurutu, Equador e Seridó) foram classificadas como rochas paraderivadas pertencente ao Neoproterozoico. $\mathrm{O}$ intercruzamento destas informações permitiu gerar dez subclasses: rochas metamórficas ortoderivadas arqueanas, rochas metamórficas ortoderivadas paleoproterozoicas, rochas metamórficas paraderivadas neoproterozoicas, rochas ígneas plutônicas neoproterozoicas, rochas ígneas vulcânicas mesozoicas, rochas sedimentares siliciclásticas mesozoicas, rochas sedimentares carbonáticas mesozoicas, rochas ígneas vulcânicas cenozoicas, coberturas sedimentares consolidadas do Paleógeno e coberturas sedimentares inconsolidadas do Neógeno.

Para agrupar estas classes no âmbito digital, foi carregado o dado geográfico vetorial geologia. shp na plataforma ArcGIS. Este arquivo apresenta um conjunto de dados alfanumérico associado aos objetos espaciais. Cada entidade espacial (linha) é caracterizada por uma série de atributos (colunas). Desta forma, para separar as subclasses, foi realizada uma seleção das entidades que apresentavam o mesmo atributo. Para isto, foi utilizado o "Select by Attributes" das opções da tabela. Por exemplo, foram selecionadas todas as unidades das coberturas sedimentares consolidadas do Paleógeno, que incluem o Grupo Barreiras, as Formações Potengi, Serra dos Martins e Tibau.

Após selecionados, os dados foram exportados para um novo arquivo vetorial, constituindo uma "pré-forma" de cada subclasse. Em seguida, todas as pré-formas foram carregadas no ArcGIS e cada grupo foi submetido a fusão. Para tal, foi utilizada a função "Merge" da Barra do Editor.

Para compor as estruturas tectônicas, optou-se por manter somente aquelas que foram expressivas ao longo da história geológica do estado, que foram as Zona de Cisalhamento Portalegre e Zona de Cisalhamento Picuí-João Câmara. Desta forma, foram excluídas todas as demais estruturas do arquivo vetorial.

Após classificar e generalizar todos estes dados geológicos foram estabelecidas as variáveis visuais mais adequadas para a representação dos dados. Para isto, foram escolhidas as variáveis visuais cor e valor nos modos de implantação zonal, linear e pontual. As cores e valores escolhidos resultam de uma combinação e adequação daqueles utilizados no Mapa Geológico do Estado do Rio Grande do Norte e no Mapa Geodiversidade do Estado do Rio Grande do Norte.

Em seguida foram adicionados no mapa principal as bases planimétricas (rodovias, sedes municipais, hidrografia). Além disso, foram incluídos os elementos representativos de um mapa (indicação do Norte, escala, grid, legenda, projeções).

Foram selecionadas também quatro temas para compor os mapas secundários: Eras Geológicas, Classes de Rochas, Domínios Geomorfológicos e Padrões de Relevo.

O Mapa de Eras Geológicas foi confeccionado a partir do arquivo vetorial geologia.shp. Para tal, foram aplicadas as mesmas técnicas de generalização de dados utilizadas no Mapa geológico simplificado. Sendo que, para este caso, foi levado em consideração apenas o atributo "ERA_MAXIMA”. Após as operações de generalização, foram aplicadas as variáveis visuais cor e valor de acordo com a Tabela Cronoestratigráfica Internacional de Cohen, Finney, Gibbard \& Fan (2013).

Assim como o mapa anterior, a confecção do Mapa de Classes de Rochas seguiu os mesmos procedimentos de generalização, sendo considerado apenas o atributo "CLASSE_ROC". A variável adotada para representação foi cor, sendo vermelho para as rochas ígneas, magenta para as metamórficas e tons de amarelo para as sedimentares.

Os Mapas de Domínios Geomorfológicos e Mapas de Padrões de Relevo foram reproduzidos do trabalho de Dantas \& Ferreira (2010). Para tal reprodução, aplicou-se o georreferenciamento seguido de vetorização do mapa digital. As camadas vetoriais produzidas foram ainda colocadas sobre um Modelo Digital de Terreno (MDT) produzidos a partir da imagem raster SRTM obtida no website https://earthexplorer.usgs.gov/.

\section{Resultados e Discussão}

A simplificação da informação geológica contida no Mapa Geológico do Estado do Rio Grande do Norte, escala 1:500.000, de 2006 produziu informações significativas e concisas que podem ser facilmente lidas em todos os mapas produzidos neste artigo.

No total, foram confeccionados cinco mapas temáticos qualitativos, sendo um deles tido como

\begin{tabular}{c|c}
\hline (C) Terrae Didat. & Campinas, SP \\
\hline
\end{tabular}


MAPA GEOLÓGICO SIMPLIFICADO DO ESTADO DO RIO GRANDE DO NORTE
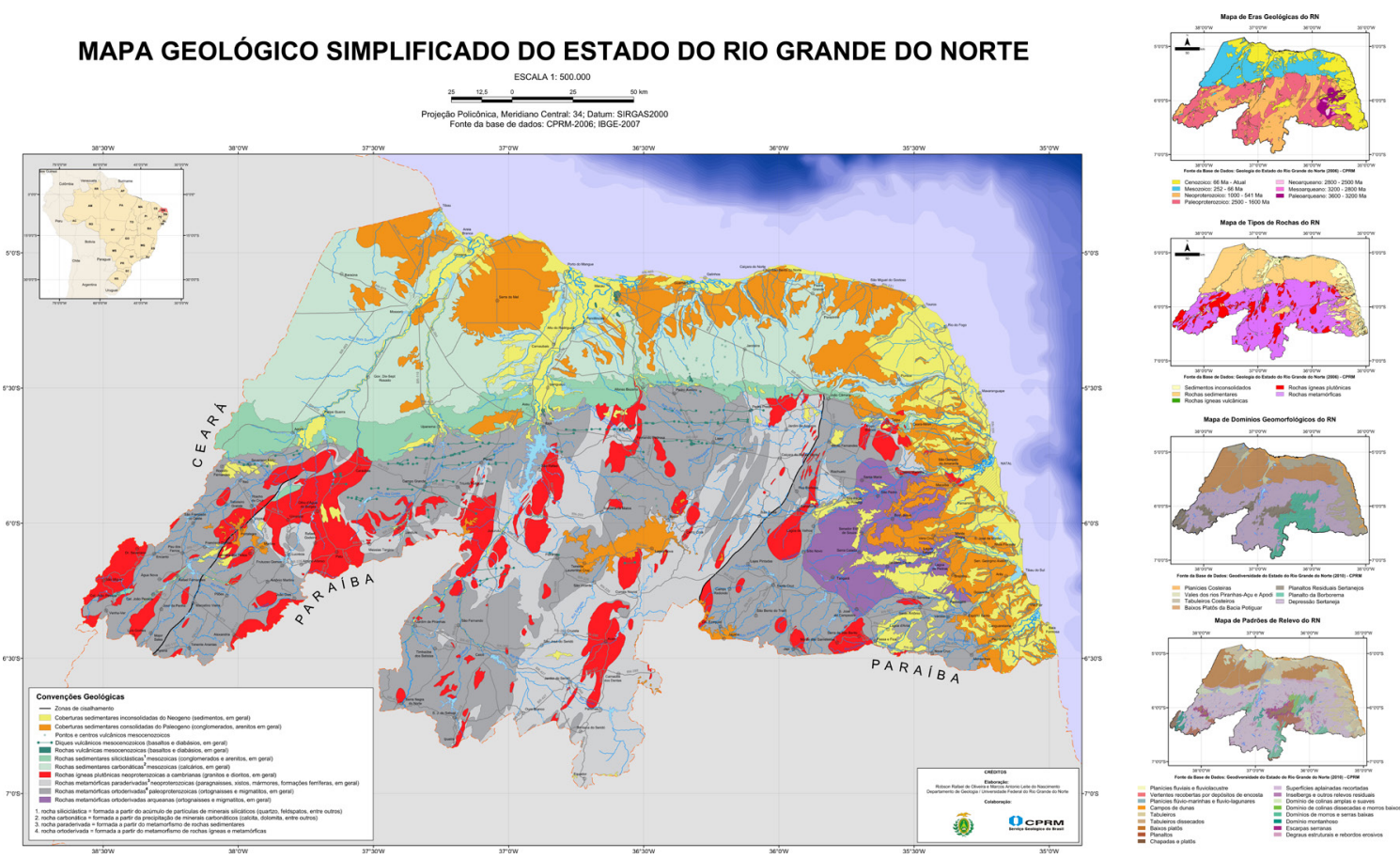

Figura 1. Mapa Geológico Simplificado do Estado do Rio Grande do Norte

principal, na escala 1:500.000, enquanto que os demais, tidos como encartes, na escala 1:2.500.000. O frame principal, denominado Mapa Geológico Simplificado do Estado do Rio Grande do Norte, expõe a generalização das 64 unidades litoestratigráficas e das diversas estruturas tectônicas que compõem o estado. Os frames secundários, encartes, constituem informações complementares a respeito do meio físico, e, incluem o Mapa de Eras Geológicas, o Mapa de Classes de Rochas, o Mapa de Domínios Geomorfológicos e o Mapa de Padrões de Relevo. O conjunto de todos estes frames constitui um mapa em layout formato A0 (acessar em https://www.dropbox.com/s/qrdabcl9z717ojj/ MapaGeologicoSimplificadodoEstadodoRioGrandedoNorte- $116 \mathrm{~cm} \times 7120 \mathrm{cmm} \cdot p d f ? d l=0)$, representado esquematicamente na Figura 1.

\section{Frame principal}

No Mapa Geológico Simplificado do Estado do Rio Grande do Norte é possível representar três grandes grupos litoestratigráficos, dez subgrupos de unidades e duas grandes estruturas tectônicas. A figura 2 exibe a comparação entre o empilhamento litoestratigráfico do mapa geológico produzido pelo Serviço Geológico do Brasil - CPRM (Angelim et al., 2006) e o das unidades do mapa simplificado proposto neste artigo. Os grandes grupos são representados por: i) Embasamento pré-cambriano e plutonismo neoproterozoico; ii) Bacias sedimentares cretáceas e vulcanismo mesozoico; e iii) Coberturas sedimentares e vulcanismo cenozoico

Estes grupos subdividem-se em dez subgrupos, nas proporções exibidas na figura 3 e distribuídas no território potiguar segundo a figura 4 . Esquematicamente, o território potiguar é composto por:

i) Embasamento pré-cambriano e plutonismo neoproterozoico

a. Rochas metamórficas ortoderivadas arqueanas

b. Rochas metamórficas ortoderivadas paleoproterozoicas

c. Rochas metamórficas paraderivadas neoproterozoicas

d. Rochas ígneas plutônicas neoproterozoicas

ii) Bacias sedimentares cretáceas e vulcanismo mesozoico

e. Vulcanismo mesozoico

f. Rochas sedimentares siliciclásticas mesozoicas

g. Rochas sedimentares carbonáticas mesozoicas

iii) Coberturas sedimentares e vulcanismo cenozoico

\begin{tabular}{c|c|c|c|c|c}
\hline (C) Terrae Didat. & Campinas, SP & v.15 & $1-13$ & 2019 \\
\hline \multicolumn{4}{|l|}{}
\end{tabular}




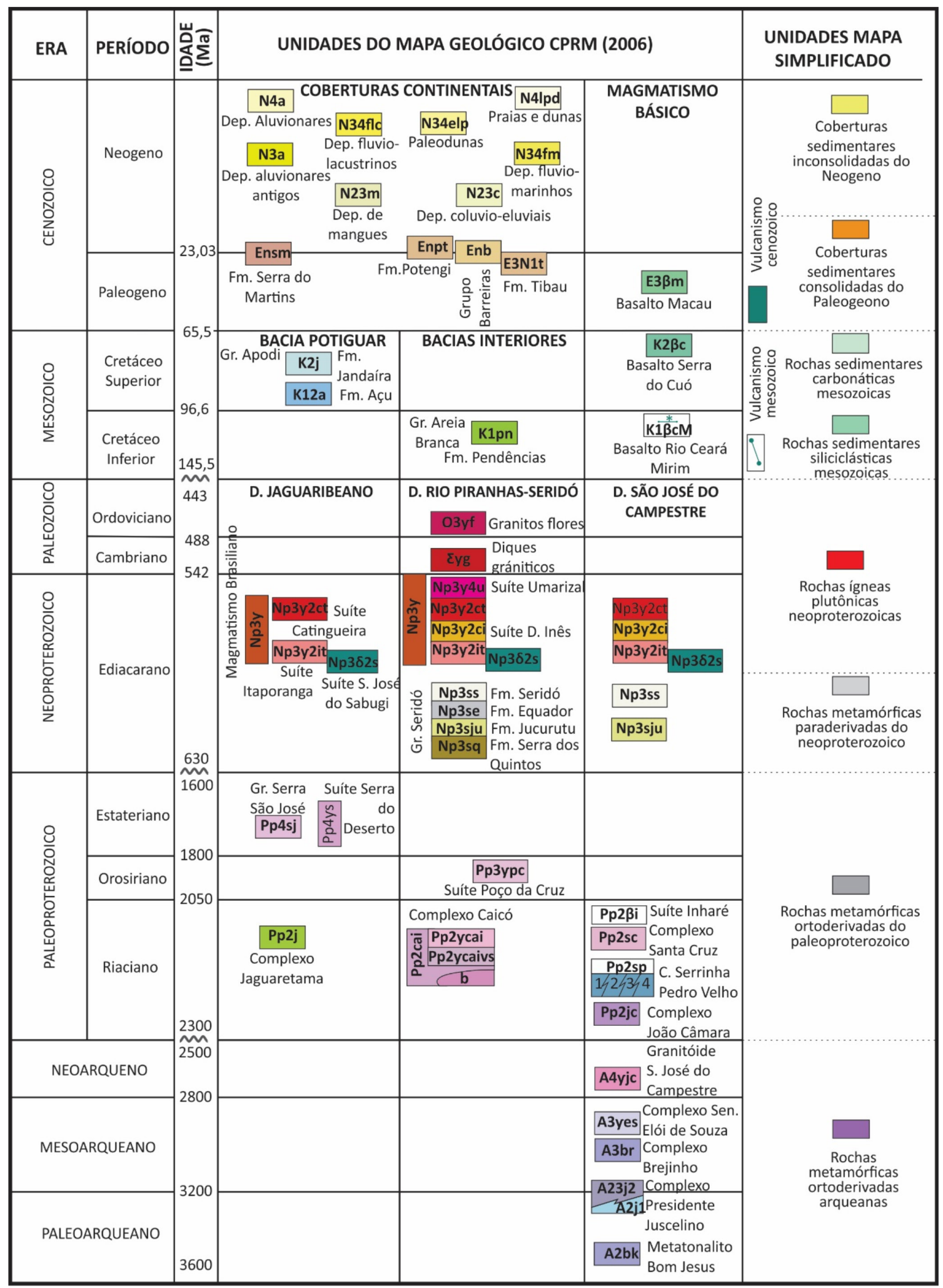

Figura 2. Comparação entre o empilhamento litoestratigráfico do Mapa Geológico do Estado do Rio Grande do Norte (Angelim et al., 2006) e das unidades propostas para o Mapa Geológico Simplificado do Estado do Rio Grande do Norte 


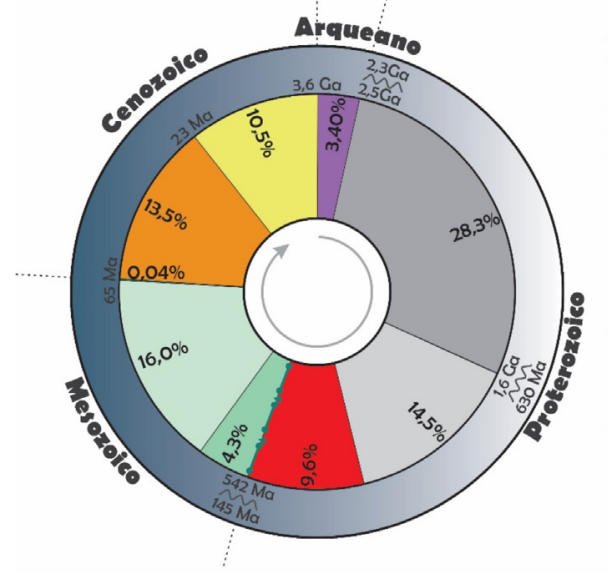

M Hiato temporal

COBERTURAS SEDIMENTARES E VULCANISMO CENOZOICO

$\square$ Coberturas sedimentares inconsolidadas do neogeno

Coberturas sedimentares consolidadas do paleogeno

Vulcanismo cenozoico

BACIAS SEDIMENTARES CRETÁCEAS E VULCANISMO MESOCENOZOICO

$\square$ Rochas sedimentares carbonáticas cretáceas

$\square$ Rochas sedimentares siliciclásticas cretáceas

. . Vulcanismo mesozoico

EMBASAMENTO PRÉ-CAMBRIANO E PLUTONISMO NEOPROTEROZOICO

Rochas igneas plutônicas neoproterozoicas

Rochas metamórficas paraderivadas neoproterozoicas

Rochas metamórficas ortoderivadas do paleoproterozoico

Rochas metamórficas ortoderivadas do arqueano

Figura 3. Composição do estado do Rio Grande do Norte de acordo com a segmentação, com base nos diferentes grupos, subgrupos e idades das rochas

h. Vulcanismo cenozoico

i. Coberturas sedimentares consolidadas do Paleógeno

j. Coberturas sedimentares inconsolidadas do Neógeno

Em relação às estruturas tectônicas, o território é segmentado por duas grandes zonas de cisalhamento, denominadas Zona de Cisalhamento Portalegre $(\mathrm{ZCPa})$ e Zona de Cisalhamento Picuí - João câmara (ZCPJ), localizadas, respectivamente, no oeste e no leste do estado.

\section{Embasamento Pré-cambriano e Plutonismo Neoproterozoico}

Este grupo ocupa $55,80 \%$ do território potiguar e situa-se na porção centro-sul do estado. Compreende rochas metamórficas e ígneas com idades variando do Arqueano ao Proterozoico (3,45 Ga até $541 \mathrm{Ma}$ ). Correspondendo ao maior grupo em extensão areal e temporal.

É representado pelas unidades de rochas metamórficas ortoderivadas arqueanas (Domínio São José do Campestre), rochas metamórficas ortoderivadas paleoproterozoicas (Complexo Caicó dos domínio Rio Piranhas-Seridó e Jaguaribeano) e rochas metamórficas paraderivadas neoproterozoicas (Grupo Seridó do Domínio Rio Piranhas-Seridó). Intrusivas nestas litologias precedentes encontram-se rochas ígneas (plutônicas) oriundas das manifestações magmáticas que acometeram a Província Borborema durante o Ciclo Brasiliano (Neoproterozoico) (Fig. 5).

\section{Rochas metamórficas ortoderivadas arqueanas}

Esta unidade localiza-se no extremo leste do Rio Grande do Norte e corresponde a 3,40\% do território potiguar. É representada, em sua maior parte, por ortognaisses de composição tonalítica a granodiorítica com vários graus de migmatização (Fig. 6a). Suas idades variam de 3,41 Ga até 2,7 Ga. Inclui o fragmento de crosta mais antiga da Plataforma Sul-Americana, o Maciço Bom Jesus, com 3,41 Ga (Dantas et al., 2004; Souza et al., 2016) (Fig. 6b).

\section{Rochas metamórficas ortoderivadas paleoproterozoicas}

Esta unidade abrange o extremo oeste e boa parte do centro sul do estado. É a unidade de maior extensão areal, totalizando $28,30 \%$. É caracterizada por rochas metaplutônicas gnáissicas/migmatíticas de composição tonalítica a granodiorítica, incluindo corpos de augen gnaisses de composição monzonítica a granítica, além de algumas metavulcanossedimentares associadas (Figs. 6c, 6d). Suas idades variam de 2,27 $\mathrm{Ga}$ até 1,67 Ga.

\section{Rochas metamórficas paraderivadas neoproterozoicas}

Esta unidade ocorre na porção centro-leste do estado, segundo uma faixa de direção NE-SW, ocupando $14,50 \%$ do território. É caracterizada por rochas metassedimentares (xistos, paragnaisses, mármores, calciossilicáticas, quartzitos, metaconglomerados) e metavulcânicas básicas e intermediárias subordinadas (Figs. 6e, 6f). O protólito sedimentar apresenta idade de deformação e meta- 

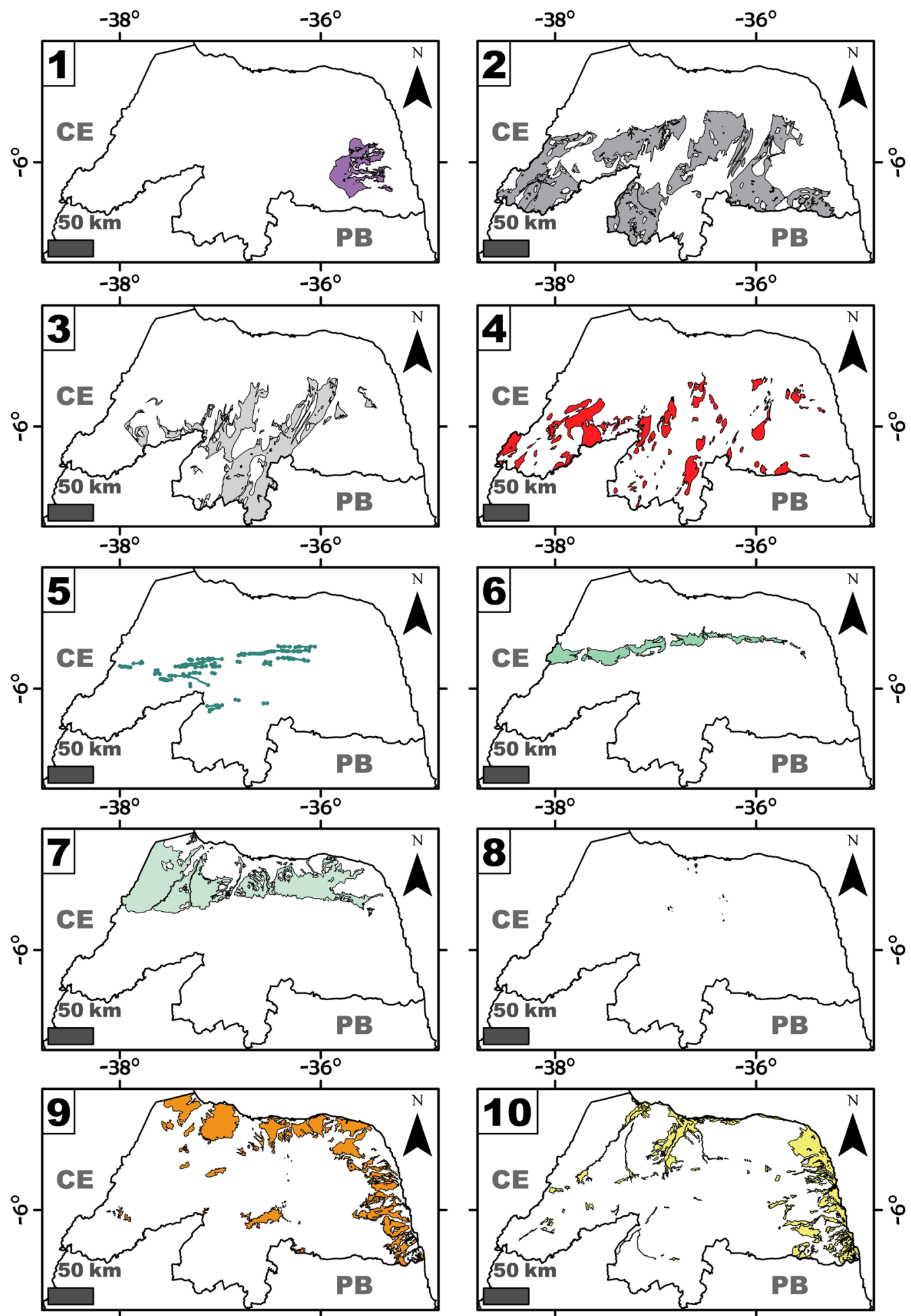

Figura 4. Distribuição dos subgrupos propostos para o Rio Grande do Norte. Categorias: 1- Rochas metamórficas ortoderivadas arqueanas; 2- Rochas metamórficas ortoderivadas paleoproterozoicas; 3- Rochas metamórficas paraderivadas neoproterozoicas; 4- Rochas ígneas plutônicas neoproterozoicas; 5- Vulcanismo mesozoico; 6- Rochas sedimentares siliciclásticas mesozoicas; 7- Rochas sedimentares carbonáticas mesozoicas; 8- Vulcanismo cenozoico; 9- Coberturas sedimentares consolidadas do Paleógeno; e 10- Coberturas sedimentares inconsolidadas do Neógeno 
morfismo em torno de $650 \mathrm{Ma}$ (Van Schmus et al., 2003). Nesta unidade ocorrem os principais depósitos minerais metálicos do estado.

\section{Rochas ígneas plutônicas neoproterozoicas}

Esta unidade totaliza 9,6\% do território e engloba corpos plutônicos que se distribuem por toda a porção centro-sul do estado. Compreendem suítes de granitos, sienitos, tonalitos, monzonitos, gabros e dioritos, que ocorrem sob a forma de batólitos, stocks e diques (Figs. 6g, 6h). Diversos autores (dados sumarizados em Nascimento et al., 2015) sugerem que o episódio plutônico principal tenha ocorrido entre 590-570 Ma. Tardiamente a este evento plutônico, datado entre 515 e $510 \mathrm{Ma}$ (Baumgartner et al., 2006), ocorrem inúmeros diques e pequenos corpos de pegmatitos. Estes abrigam mineralizações de Ta-

Figura 6. Feições de campo das rochas do Grupo Embasamento Pré-cambriano e Plutonismo Neoproterozoico. (a) Ortognaisse migmatizado do Complexo Presidente Juscelino representativo da unidade rochas metamórficas ortoderivadas arqueanas (Foto: Ana Karoline Bezerra, 2011); (b) Um dos fragmentos mais antigo da plataforma sul-americana denominado de Serra Caiada, com 3,3 Ga (Souza et al. 2016) (Foto: Assis Barbosa, sem data); (c) Ortognaisse típico do Complexo Caicó, exibindo bandamento gnáissico dobrado (Foto: Marília Barbosa, 2012); (d) Augen gnaisse com feldspatos (em róseo) em formato elíptico centimétrico (Foto: Robson Rafael, 2013); (e) Micaxisto da Formação Seridó intensamente dobrado (Foto: Robson Rafael, 2013). (f) Mármore bandado/dobrado da Formação Jucurutu em pedreira (Foto: Marília Barbosa, 2016). (g) Feições de mistura de magmas entre granito porfirítico (cinza claro) e diorito (cinza escuro) (Foto: Marcos Nascimento, 2010); (h) Fenocristais de feldspato potássico encontrados nas rochas do batólito de Monte das Gameleiras (Foto: Marcos Nascimento, 2010)

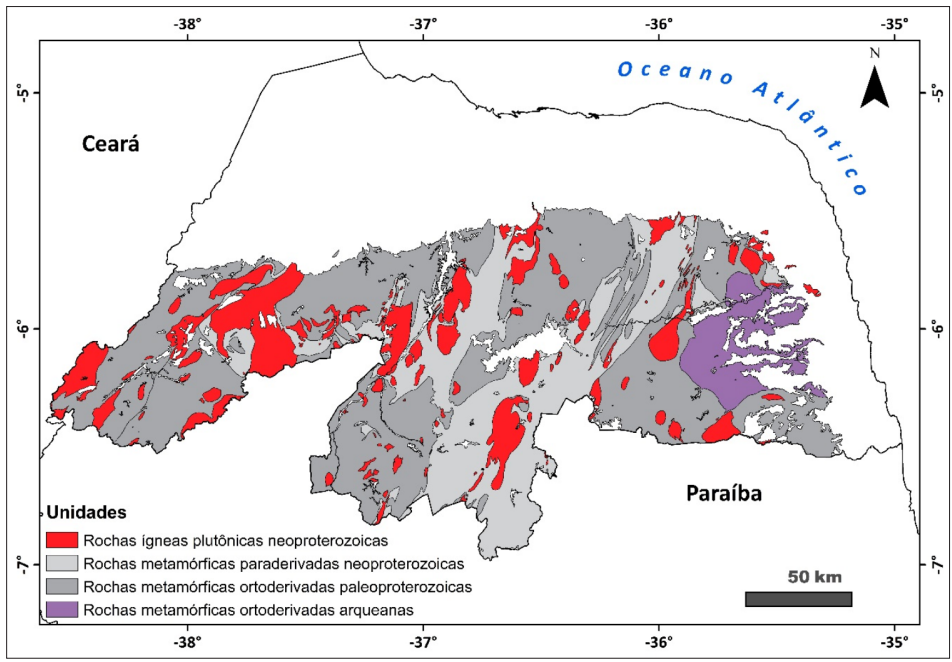

Figura 5. Unidades que compõem o grupo Embasamento Pré-cambriano e Plutonismo Neoproterozoico
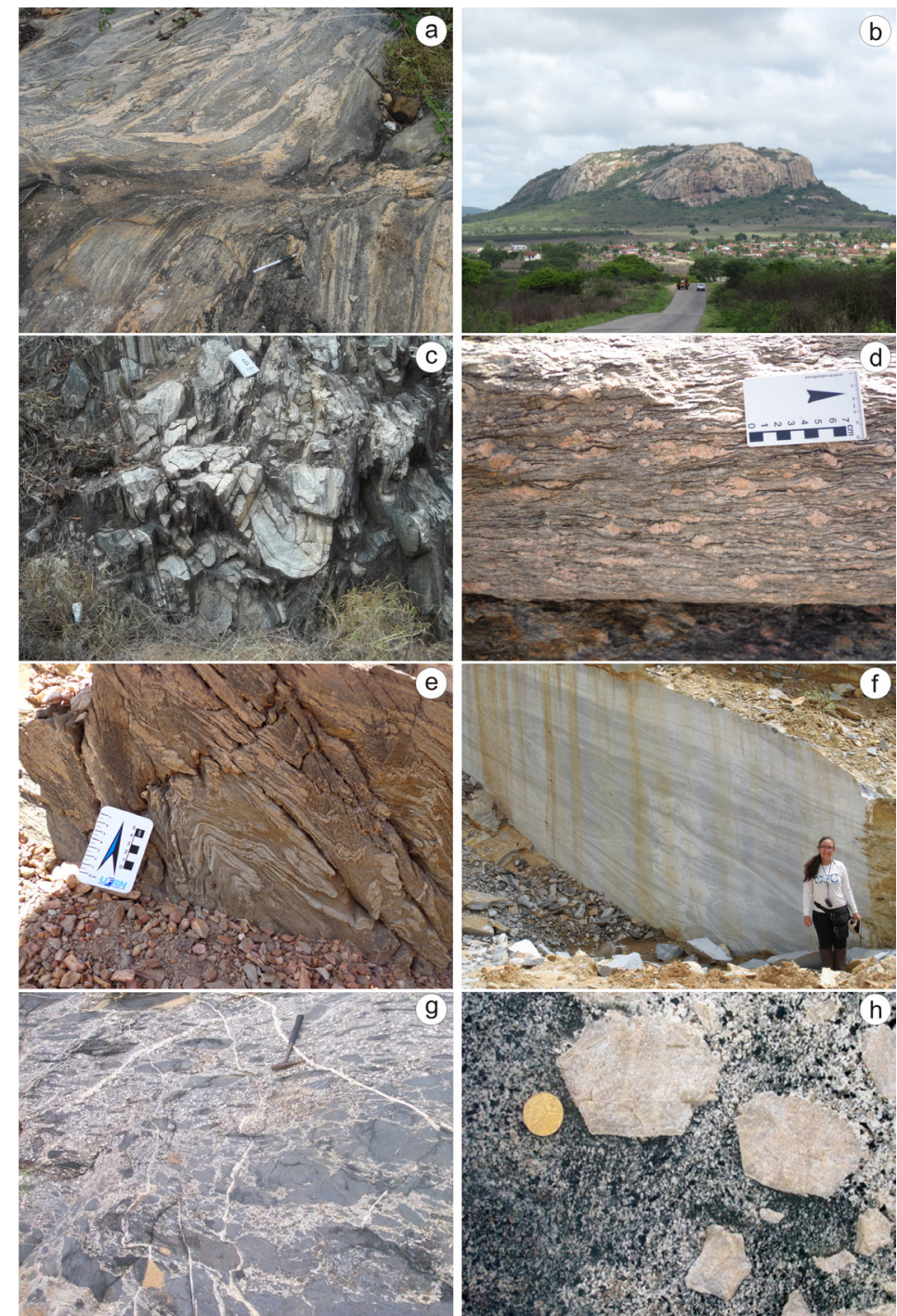

Campinas, SP

v. 15

$1-13$

2019 
-Nb, Sn, Be e Li, associados a Província Pegmatítica da Borborema,

além das mineralizações de ouro em veios de quartzo (Legrand et al., 1993; Silva, 1993). Estes pegmatitos ocorrem intrusivos na unidade de Rochas metamórficas paraderivadas neoproterozoicas e em seu prolongamento para o sul em forma de diques e de pequenos corpos. Apesar de sua expressividade, no banco de dados adotado neste trabalho os pegmatitos não são representados cartograficamente devido a escala.

\section{Bacias Sedimentares Cretáceas e Vulcanismo Associado}

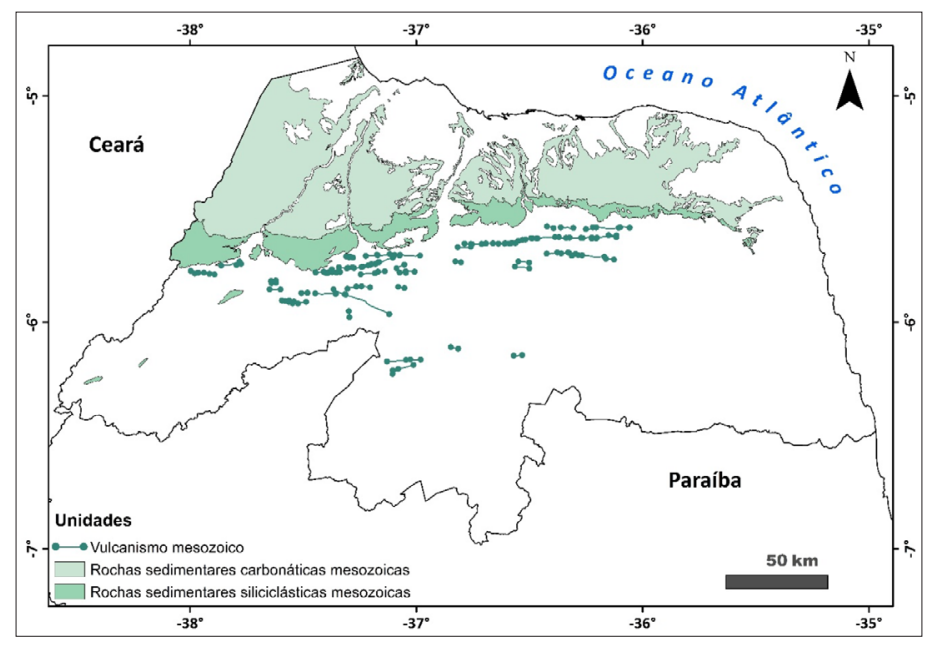

Figura 7. Unidades que compõem o grupo Bacias Sedimentares Cretáceas e Vulcanismo Mesocenozoico
Este grupo aflora em 20,34\% do território potiguar, ocorrendo na porção norte e em algumas áreas do extremo oeste do estado. Compreende rochas sedimentares e vulcânicas básicas, oriundas dos esforços distensionais, durante o Cretáceo, para separação das placas sul-americana e africana.

É representado pelas unidades de rochas vulcânicas mesozoicas, rochas sedimentares siliciclásticas mesozoicas e rochas sedimentares carbonáticas mesozoicas (Fig. 7).

\section{Rochas vulcânicas mesozoicas}

Esta unidade associa-se a implantação das bacias sedimentares cretáceas e agrupa dois eventos magmáticos. O primeiro, ocorrendo entre 120 e $140 \mathrm{Ma}$ (com pulso principal em $132 \mathrm{Ma}$ ) (Pessoa Neto et al., 2007), compreende diques de diabásio toleíticos fortemente orientados no sentido E-W e intrusivos no embasamento cristalino a sul da unidade siliciclástica da Bacia Potiguar (Fig. 8a). O segundo, ocorrendo em $93 \mathrm{Ma}$, corresponde a derrames de diabásio com tendência alcalina (Pessoa Neto et al., 2007). Por ocorrer em formato de diques e pequenos derrames, cuja largura é na escala métrica e o comprimento irregular, a extensão areal desta unidade não foi levada em consideração neste trabalho.

\section{Rochas sedimentares siliciclásticas mesozoicas}

Esta unidade corresponde a 4,3\% do território potiguar, ocorrendo na porção central do estado e em algumas pequenas áreas do extremo oeste. Corresponde às rochas siliciclásticas das bacias, que incluem conglomerados, arenitos finos a muito grossos, siltitos e folhelhos (Figs. 8b, 8c). Estes litotipos foram depositados em sistemas flúvio-lacustres, flúvio-deltaicos e flúvio-marinhos
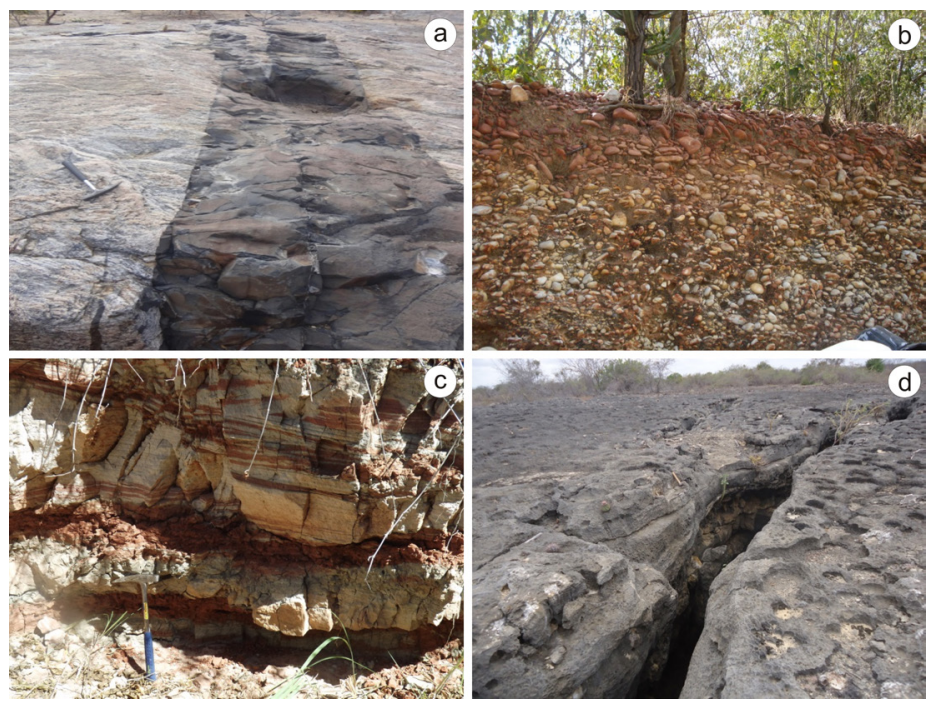

Figura 8 - Feições de campo das rochas do Grupo Bacias Sedimentares Cretáceas e Vulcanismo Associado. (a) Diques de diabásio Rio Ceará Mirim (em preto) cortando rochas do embasamento cristalino (cinza claro) (Foto: Marilia Barbosa, 2013); (b) Conglomerado polimítico e polimodal dos terraços da Formação Açu (Foto: Ana Karoline Bezerra, 2011); (c) Arenito fino da Formação Açu exibindo alternâncias de camadas claras e vermelhas (Foto: Alana Dantas, 2015); (d) Calcarenito da Formação Jandaíra exibindo estruturas de carstificação (Foto: Micael Damasceno, 2016) 
entre $110 \mathrm{Ma}$ e $65 \mathrm{Ma}$ (Pessoa Neto et al., 2007).

\section{Rochas sedimentares carbonáticas mesozoicas}

Esta unidade ocorre como uma faixa no extremo norte do estado e ocupa $16,0 \%$ do território potiguar. Compõe-se predominantemente por calcarenito e calcilutitos bioclásticos, apresentando intercalações de arenitos, folhelhos, margas e evaporitos (Figura 8d). Estes litotipos foram depositados em sistemas deposicionais de planície de maré, laguna rasa, plataforma rasa e mar aberto (Pessoa Neto et al., 2007). Representam ainda os litotipos que exibem a maior quantidade de fósseis da Bacia Potiguar, sejam eles macrofósseis ou microfósseis, além de ocorrência de cavernas. Seu conteúdo fossílifero indica deposição entre $100 \mathrm{Ma}$ e $65 \mathrm{Ma}$.

\section{Coberturas Sedimentares e Vulcanismo Cenozoico}

Este grupo corresponde a 24,04\% do território potiguar, abrangendo toda a faixa próxima a linha de costa e algumas porções interioranas do estado (Fig. 9). Encerra coberturas sedimentares consolidadas e inconsolidadas, além de algumas vulcânicas associadas. Apresenta idades que variam de $66 \mathrm{Ma}$ até o recente.

\section{Vulcanismo cenozoico}

Esta unidade corresponde ao terceiro e último evento magmático que atuou na Bacia Potiguar, entre 70-6 Ma (Pessoa Neto et al., 2007). Ocupa $0,04 \%$ do território potiguar e distribui-se na porção centro norte do Rio Grande do Norte. Trata-se de basaltos com filiação alcalina, contendo xenólitos peridotíticos. Ocorrem sob a forma de derrames, diques, plugs e necks. Podem ocorrer intercalados a algumas coberturas sedimentares consolidadas. O Pico do Cabugi é um exemplo icônico da unidade (Fig. 10).

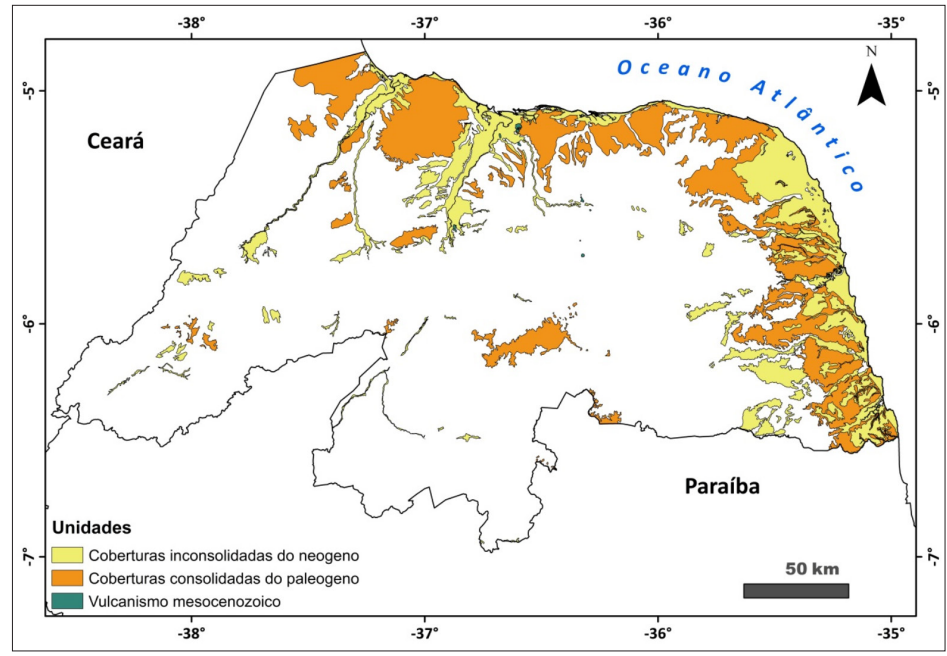

Figura 9. Unidades que compõem o grupo Coberturas sedimentares e vulcanismo cenozoico

\section{Coberturas sedimentares consolidadas do Paleógeno}

Esta unidade corresponde a $13,50 \%$ do território potiguar, ocorrendo ao longo de uma faixa próxima ao litoral do estado e no topo de algumas serras interioranas. Apresentam-se sob a forma de tabuleiros e chapadas de relevo plano a ondulado
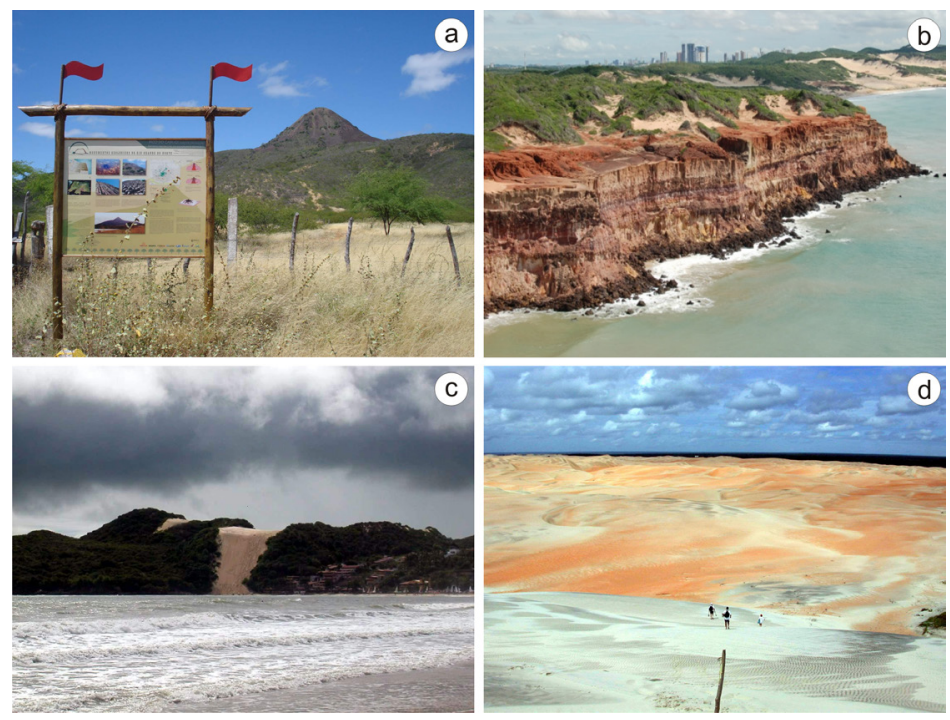

Figura 10. Feições de campo das rochas do Grupo Coberturas Sedimentares e Vulcanismo Cenozoico. (a) Pico do Cabugi, ao fundo, trata-se de um neck vulcânico oriundo do vulcanismo Macau (Foto: Marcos Nascimento, 2012); (b) Falésias litorâneas da Barreira do Inferno, as quais são constituídas por conglomerados e arenitos em tons creme avermelhados e arenitos ferruginosos (beachrocks) de cor escura. Sobre eles assentam as coberturas inconsolidadas do Neógeno (Foto: Centro de Lançamento da Barreira do Inferno (CLBI), sem data); (c) Dunas vegetadas que constituem a figura turística Morro do Careca, na Praia de Ponta Negra, da cidade do Natal/RN (Foto: Marcos Nascimento, 2014); (d) Dunas do Rosado em Porto do Mangue. Estas dunas abrangem mais de $10 \mathrm{~km}^{2}$ de extensão; suas areias apresentam vários tons de rosa. (Foto: Marcos Nascimento, 2011). 
(Figura 10b). Tendo como litotipos principais os conglomerados, arenitos finos a grossos, siltitos e concreções ferruginosas. Estas rochas recobrem indistintamente as unidades do embasamento pré-cambriano e da porção aflorante da Bacia Potiguar. Devido ao seu pobre conteúdo fossilífero, a idade desta unidade é motivo de discussão de diversos pesquisadores, sendo considerado, em média, 23 Ma para a idade da deposição destes sedimentos.

\section{Coberturas sedimentares inconsolidadas do Neógeno}

Esta unidade ocupa 10,50\% do território potiguar e ocorrem nos grandes vales fluviais do estado (Rios Açu/Piranhas, Potengi, Apodi, Ceará Mirim) e ao longo da costa Atlântica. Incluem-se depósitos fluviais (areias aluvionares e terraços), deltaicos (sedimentos dos deltas dos Rios Açu e Potengi), de praia (beachrocks, recifes areníticos e areias de praias)
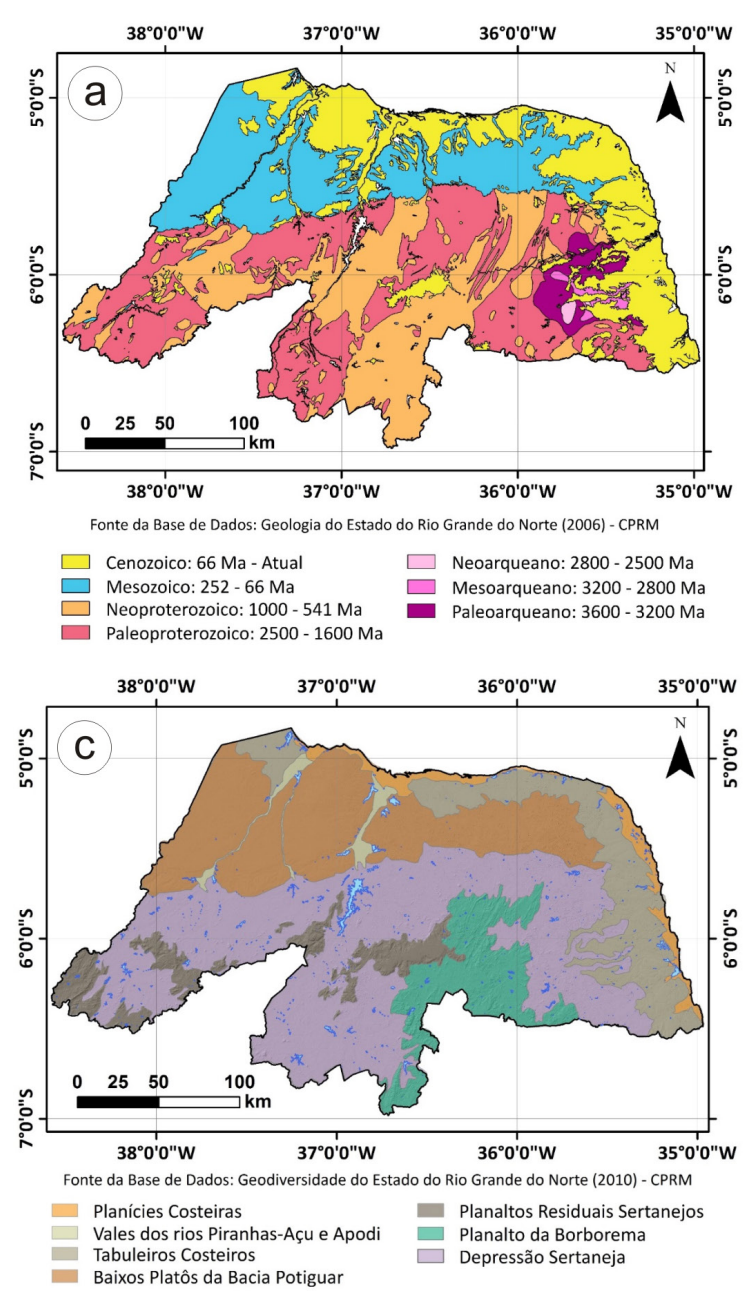

e dunas eólicas (Figuras 10c, 10d). Em síntese, estão relacionadas aos sistemas de drenagens e praias.

\section{Frames Secundários}

Para compor o mapa final foram adicionados os encartes temáticos, Eras Geológicas, Classes de Rochas, Domínios Geomorfológicos e Padrões de Relevo (Figura 11).

\section{Mapa de eras geológicas}

O Mapa de Eras Geológicas (Figura 11a) permite visualizar a distribuição espacial do atributo idade geológica no estado do Rio Grande do Norte. Observa-se a predominância das unidades pré-cambrianas (Arqueano ao Neoproterozoico) frente às unidades do eón Fanerozoico (Mesozoico ao recente). Este mapa faz correspondência ao valor adotado na Tabela cronoestratigráfica de Cohen et al. (2013).
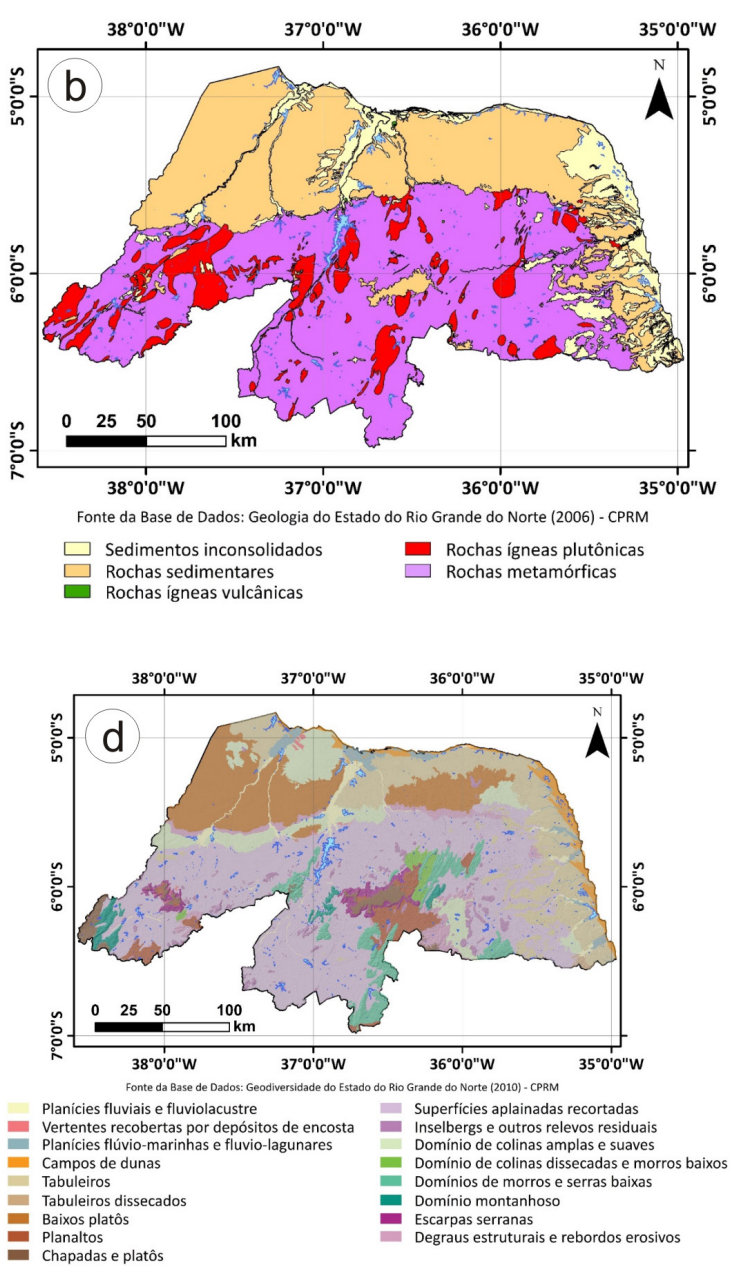

Figura 11. Diferentes encartes relacionados a temas geológicos e geomorfológicos. (a) Mapa de Eras Geológicas; (b) Mapa de Classes de Rochas; (c) Mapa de Domínios Geomorfológicos; (d) Mapa de Padrões de Relevo 


\section{Mapa de classes de rochas}

O Mapa de Classes de Rochas (Figura 11b) exibe a distribuição espacial do atributo tipo rochoso. Nesta representação, constata-se o predomínio das rochas cristalinas (ígneas e metamórficas) em relação às rochas sedimentares. Observação já verificada na descrição do Mapa Geológico Simplificado.

\section{Mapa de domínios geomorfológicos}

O Mapa de Domínios Geomorfológicos (Figura 11c) trata-se de um produto extraído integralmente do trabalho de Dantas e Ferreira (2010). Nesta concepção, o estado do Rio Grande do Norte é compartimentado em sete domínios geomorfológicos, os quais são reflexos do substrato (tipo rochoso) e das dinâmicas internas e externas atuantes. Os sete domínios são: Depressão Sertaneja, Planalto da Borborema, Planalto Residuais Sertanejos, Baixos Platôs da Bacia Potiguar, Tabuleiros Costeiros, Vale dos rios Piranhas-Açu e Apodi e Planícies Costeiros.

\section{Mapa de padrões de relevo}

O Mapa de Padrões de Relevo (Figura 11d) também foi extraído de Dantas e Ferreira (2010). Neste mapa, a partir da análise de dados SRTM, os domínios geomorfológicos desdobram-se em 17 padrões de relevo.

\section{Considerações Finais}

Como dizia Paulo Freire: "Educação não transforma o mundo. Educação muda pessoas. Pessoas transformam o mundo". Com o conjunto cartográfico produzido neste artigo pretende-se aproximar a sociedade com o meio físico, mais especificamente com a Geologia.

Este trabalho propõe a representação cartográfica de dados geológicos de maneira significativa e sumarizada em ambiente digital e impresso. Nos produtos obtidos observa-se significativa melhoria no processo de comunicação visual entre o mapa e o leitor. Foi eliminado um excesso de informação que propicia dispersão da compreensão do usuário e dificulta na integração e representação da realidade. Desta forma, estes mapas poderão ser utilizados por pesquisadores de diversas áreas, gestores e leitores que necessitem compreender (melhor) o meio abiótico sem possuir uma significativa bagagem teórica.
Verificou-se também a funcionalidade do Sistema de Informação Geográfica (SIG) na produção cartográfica e compreensão do meio físico. Nesta plataforma é possível intercruzar informações de fontes e temáticas diversas para representar e analisar o espaço geográfico. O SIG revelou-se uma poderosa ferramenta para compreensão do espaço geográfico e implantação de um desenvolvimento sustentável. Seu uso permite ainda que a Cartografia atinja uma maior extensão e alcance na representação e compreensão de dados de cunho espacial.

Recomenda-se que a percepção visual da informação contida nos mapas produzidos seja avaliada junto ao público, de forma a proporcionar futuras adequações do material.

\section{Referências}

Angelim, L. A. A., Medeiros, V. C. \& Nesi, J. R. (2006). Mapa geológico do Estado do Rio Grande do Norte. 1:500.000. Recife: CPRM/FAPERN. (Progr. Geol. Brasil. Proj. Geol. e Rec. Min. Estado Rio Grande do Norte). URL: http://www.cprm.gov.br/publique/media/geologia_basica/cartografia_regional/ mapa_rio_grande_norte.pdf. Acesso 07.01.2019.

Baumgartner, R., Romer, R. L., Moritz, R., Sallet, R., Chiaradia, M. (2006). Columbite-tantalite-bearing granitic pegmatites from the Seridó Belt, Northeastern Brazil: genetic constraints from $\mathrm{U}-\mathrm{Pb}$ dating and $\mathrm{Pb}$ isotopes. The Canadian Mineralogist, 44, 69-86.

Borges, U. N. (2013). Proposta de representação gráfica de dados da geodiversidade utilizando cartografia temática e tecnologias da geoinformação (Dissertação de mestrado). Recife, Brasil, Programa de Pós-Graduação em Geociências.

Cohen, K. M., Finney, S., Gibbard, P. L., \& Fan J.-X. (2013). International chronostratigraphic chart: International Commission on Stratigraphy. Episodes, 36(3), 199-204. URL: http://www.stratigraphy.org/icschart/cohen2013_episodes.pdf. Acesso 07.01.2019.

CPRM. (2009). Mapa Geodiversidade do Estado do Rio Grande do Norte: Escala 1:500.000. Recife: CPRM/ Serv. Geol. Brasil, SGM, MME. URL: http:// rigeo.cprm.gov.br/jspui/handle/doc/14709. Acesso 07.01.2019.

Dantas, E. D. \& Ferreira, R. V. (2010). Relevo. In: Pfaltzgraff, P. A. S. \& Torres, F. S. M. (Eds.), Geodiversidade do estado do Rio Grande do Norte (p.77-92). Recife: CPRM.

Dantas, E.L., Van Schmus, W.R., Hackspacher, P.C., Fetter, A.H., Brito Neves, B.B., Cordani, U., Nutman, A.P. \& Williams, I.S. (2004). The 3.43.5 Ga São José do Campestre massif, NE Brazil: 
remnants of the oldest crust in South America. Precambrian Research, 130, 113-137. doi: 10.1016/j. precamres.2003.11.002.

Iza, E. R. H. F. \& Costa, M. A. C. (2010). Mapa geológico simplificado do estado de Rondônia: uma ponte entre a comunidade acadêmica e a sociedade. In XLV Anais do Congresso Brasileiro de Geologia, Belém (769-769). Belém: SBG-Núcleo Norte.

Legrand, J. M., Melo, Jr. G., Archanjo, C. J., Salim, J., Souza, L. C. \& Maia H. N (1993). Mineralizações da Faixa Seridó: um processo hidrotermal do fenômeno tectono-magmático brasiliano. In: XV Simpósio de Geologia do Nordeste (p. 185-187). Natal: SBG-Núcleo Nordeste.

Mansur, K., Medeiros, F., Guedes, E., Guimarães, P. V., Schmitt, R., Latgé, M. (2004). Mapa Geológico Simplificado do Estado do Rio de Janeiro. As rochas nos contam sua história. URL: http://www.drm. rj.gov.br/index.php/downloads/category/63niteri? download $=459 \% 3$ Aapa-geolgico-simplificado-do-estado-do-rio-de-janeiro. Acesso 15.12.2017.

Medeiros, V. C., Amaral, C. A., Rocha, D. E. G. A., \&Santos, R. B. (2005). Programa Geologia do Brasil - PGB. Sousa. Folha SB.24-Z-A. Estados da Paraíba, Rio Grande do Norte e Ceará. Mapa Geológico. Recife: CPRM, 2005, 1 mapa, color., $66 \mathrm{~cm} \times 108 \mathrm{~cm}$. Escala 1:250.000. URL: http://rigeo.cprm.gov.br/ xmlui/handle/doc/7473. Acesso 07.01.2019.

Nascimento, M. A. L., Galindo, A. C., \& Medeiros, V. C. (2015). Ediacaran to Cambrian magmatic suites in the Rio Grande do Norte domain, extreme Northeastern Borborema Province (NE of Brazil): current knowledge. Journal of South American Earth Sciences, 58, 281-299. doi: 10.1016/j. jsames.2014.09.008

Pessoa Neto, O. C., Soares, U. M., Silva, J. G. F.,
Roesner, E. H., Florencio, C. P., \& Souza, C. A. V. (2007). Bacia Potiguar. Boletim de Geociências da Petrobras, 15(2), 357-369.

Pfaltzgraff, P. A. S. \& Torres, F. S. M. (2010). Geodiversidade do Estado do Rio Grande do Norte. Recife: CPRM. URL: http://rigeo.cprm.gov.br/xmlui/ handle/doc/16773. Acesso 07.01.2019.

Santos, R. A., Leão Neto, R., Santos, E. B. S. E., Fernandes, L. F. R., Abram, M. B., Moreira, G., Jacques, P. D., \& Nascimento, F.G.C. (2015). Mapa Geológico Simplificado do Brasil, escala: 1:6.000.000. CPRM/Serviço Geológico do Brasil, SGM, MME. Rio de Janeiro. URL: http://geobank. cprm.gov.br/pls/publico/geobank.documents. open_zipfile?id_sessao $=20160624121849 \&$ file $=\mathrm{g}$ eologicosimplificado.zip. Acesso 15.12.2017.

Silva, M. R. R. (1993). Petrographical and geochemical investigations of pegmatites in the Borborema Pegmatitic Province of Northeastern Brazil (Tese de Doutorado). Munique, Alemanha, Ludwig-Maximilians-Universität.

Souza, Z. S., Kalsbeek, F., Deng, X, Frei, R., Kokfelt, T. F., Dantas, E. L., Li, J., Pimentel, M. M., \& Galindo, A.C. (2016). Generation of continental crust in the northern part of the Borborema Province, northeastern Brazil, from Archaean to Neoproterozoic. Journal of South American Earth Sciences, 68, 68-96. doi: https://doi.org/10.1016/j. jsames.2015.10.006.

Van Schmus, W. R., Brito Neves, B. B., Williams, I. S., Hackspacher, P., Fetter, A. H., Dantas, E. L., \& Babinski, M. (2003). The Seridó Group of NE Brazil, a late Neoproterozoic pre- to syn-collisional basin in West Gondwana: insights from SHRIMP U-Pb detrital zircon ages and $\mathrm{Sm}-\mathrm{Nd}$ crustal residence (TDM) ages. Precambrian Research, 127, 287-327. doi: https://doi.org/10.1016/ S0301-9268(03)00197-9. 